\title{
A Pragmatic Analysis of the Discourse of Humour and Irony in Selected Memes on Social Media
}

\author{
Samuel F. Joshua, PhD \\ Department of Linguistics \& Communication Studies, Faculty of Humanities \\ University of Port Harcourt, Choba, Rivers State. \\ samuel joshua@uniport.edu.ng
}

DOI: http://doi.org/10.36892/ijlls.v2i2.281

\begin{tabular}{ll} 
Received: & Abstract \\
29/04/2020 & The aim of this study is to examine how memes peculiar to Nigerians on \\
\hline Accepted: & Facebook, Twitter and Instagram employ language to convey humour and irony. \\
15/05/2020 & Memes can be aptly conceptualized as internet-based entertainment contents \\
& principally propagated through social networking and micro-blogging sites \\
& which come in varied forms like pictures and written texts, written texts that may \\
Keywords: & or may not be conversational in nature, videos, animations and GIFs. This study \\
Discourse; & adopts a qualitative eclectic approach in its analysis of conversational memes \\
Humour; & which served as data gathered from Twitter, Facebook and Instagram. Guided \\
Irony; & by the General Theory of Verbal Humour (GTVH), thirty (30) conversational \\
Meme & memes were purposively selected for discussion using the guises or forms of \\
& humour as the unit of analysis on the one hand and discussions situated within \\
& empirical and theoretical postulations on the other hand. Findings from the study \\
showed that all the reactions to the originating posts exhibit some form of & incongruity and were also verbally ironical. The nature of the originating posts \\
& in line with the speech act classification were also found to be expressives and \\
& assertives. The study further revealed that three guises of humour namely \\
& sarcasm, witticism and pun were prominent in the reaction to the originating \\
posts with sarcasm constituting the major guise of humour used while also & pointing out that users on Twitter use humour more than those on Facebook and \\
Instagram.
\end{tabular}

1. INTRODUCTION

Discourse has various definitions but one way of thinking about it is as any piece of extended language, written or spoken, that has unity, meaning and purpose. According to Henry \& Tator (2002), discourse is the way in which language is used socially to convey broad historical meanings. Discourse is language identified by the social conditions of its use, by who is using it and under what conditions. Language can never be 'neutral' because it bridges our personal and social worlds. The study of discourse is entirely context-dependent because conversation involves situational knowledge beyond just words spoken or written. Often times, meaning cannot be extrapolated from an exchange merely from its verbal utterances because there are many semantic factors involved in authentic communication.

According to Bloor \& Bloor (2013), the study of discourse can involve matters like context, background information or knowledge shared between a speaker and hearer. Discourse is a joint 
activity requiring active participation from two or more people, and as such is dependent on the lives and knowledge of two or more people as well as the situation of the communication itself.

Humour has many guises or forms as confirmed by Simpson and Mayr (2010), these manifestations (both verbal and non-verbal) include but are not limited to puns, satire/sarcasms, witty remarks, slogans, captions etc. The fact is that the subject matter of humour is subjective. This is because people laugh at different things and their backgrounds may make them perceive humour differently. While some persons may find a particular statement, humorous others may find it offensive or indecorous.

Many popular forms of humour, such as parody, irony and satire, have for centuries, been oriented towards the structuring and restructuring, at both the micro- and macro-level, of personal, political and social relationships. Humour can be used as a tool of repression and ridicule by the powerful, or as a form of resistance by the less powerful, or as an instrument to help galvanize social bonds among disenfranchised groups (Simpson \& Mayr 2010).

To study discourse is to analyse the use of spoken or written language in a social context. Discourse analysis focuses on the structure of naturally occurring spoken language, as found in such discourse as conversation, interviews, commentaries and speeches. Our main focus is on text analysis and such an analysis focuses on the structure of written language in whatever form. So, this study is focusing on some peculiar type of texts found on social media commonly known as memes. According to Wikipedia, the word meme was coined by Richard Dawkins in his 1976 book The Selfish Gene as an attempt to explain how ideas replicate, mutate and evolve (Memetics). It continues that the concept of internet meme was first proposed by Mike Godwin in the June 1993 issue of Wired and in 2013, Dawkins characterized an internet meme as being a meme directly altered by human creativity. He explained that internet memes are thus a hijacking of the original idea, the very idea of a meme having mutated and evolved in this new direction. Dawkins described memes as being a form of cultural propagation, which is a way for people to transmit social memories and cultural ideas to each other. The forgoing suggests that internet memes are propagated through social networking sites as they move from one site to another, they leave footprints which can be analyzed.

A meme therefore is an evolving internet term. Traditionally, memes were very simplistic, often featuring a single word or phrase. In some cases, these words and phrases contain intentional misspellings or incorrect grammar. However, in more recent times, memes have evolved from simple image macros with text to more elaborate things such as challenges, GIFs and viral sensations (Encyclopaedia Britannica 2014). One can conveniently describe an internet meme, more commonly known simply as a meme, as a type of meme which is spread via the internet, often through social media platforms.

The paucity of scholarly articles on internet memes points to the fact there may be few studies on the pragmatic or textual analysis of memes on social media. However, other related studies on internet memes have been carried out. Shifman $(2011,2013)$ carried out two studies on internet memes. In the first of these, Shifman (2011) created a corpus of 30 prominent memetic videos from youtube.com which have generated a great deal of creative parodies. Her analysis revealed six common features between all of the videos: focus on ordinary people, flawed masculinity, humour, simplicity, repetitiveness and whimsical content. Each of these attributes marks the video as incomplete or flawed, thereby invoking further creative dialogue.

In the later paper, Shifman (2013) posits that internet memes are not single ideas or formulas that spread easily, but rather groups of content items created with awareness of each other and which share common characteristics. Shifman then isolates three possible dimensions that make up memes and which can potentially be imitated: content (referencing both the ideas and the ideologies conveyed), form (the physical format of the message perceived through the senses) and 
stance (ways in which addressers positions themselves in relation to the text, the reader/viewer and other potential speakers). While Shifman speaks about these dimensions in terms of a memetic YouTube video called "Leave Britney Alone", it applies well to memes in other formats as well and does a good job of explaining the flexibility in how many ways a meme can be altered without losing the reference to the original.

Stojchevska \& Shalveska (2018) examined memes as one of the many internet communication phenomena and the socio-linguistic features that that make memes vastly interesting to linguists and sociologists. They analyzed memes that are a blend of certain image and a piece of written text, as they are the most popular category. They further assert that the textual part of the memes they analyzed contain many features that are extremely interesting from a linguistic perspective. Linguistically, the language of memes is creative by itself. The creators of memes use neologisms, clever metaphors, slogans, fixed phrasal expressions. Abbreviations as part of informal language are also employed in memes to convey meaning in as little words/ symbols as possible. There is also the use of a patterned way of incorrect spelling and multiple intentional or unintentional grammar and syntax mistakes for humorous effect. The research also made other notable findings from the sociological perspective: that memes are generally used by specific age groups-mostly the youths who are more internet savvy than older members of the society; pop-culture has a great influence on memes thus, everything from popular movie references, to music, artistes, celebrities to television and reality shows can be included in memes, so, background knowledge is needed to understand these memes; memes are created all around the globe. They support this latter assertion by submitting that on each corner, in each and every country, in every region, city, town there are specific characteristics, traditions, cuisine, customs, moral and ethical norms as well as political and religious backgrounds. These features are unique and quite different around the world. Hence, sometimes, a meme that contains a reference specific to a certain country or region will make no sense to someone not living there.

The evolution of memes has taken a new dimension and become more popular with the advent and attendant boom of three major social networking sites-Facebook, Twitter and Instagram. According to Datareportal.com, as at April 20th, 2020, Facebook has over 2.5 billion monthly active users, Instagram has over 1 billion monthly active users and twitter has 386 million monthly active users. The statistics further showed that there is a total of 3.81 billion social media users around the world, representing $49 \%$ of the world's total population. These statistics clearly points to the fact that people from different socio-cultural and ethnic backgrounds are active users of social media and as they post messages on these social media platforms such messages can be seen in different lights and may appeal to some as humorous and vice versa. This is the case, because as earlier stated, humour is highly subjective and conditioned by context. It is in this light that the aim of this study is to examine how memes peculiar to Nigerians on Facebook, Twitter and Instagram employ language to convey humour and irony.

\section{LITERATURE REVIEW}

\section{The General Theory of Verbal Humour}

Attardo (2001) proposed the General Theory of Verbal Humour (GTVH) as a revision of the Semantic-Script Theory of Humour (SSTH). The GTVH is a broadening of SSTH out of semantics to a broader multidisciplinary theory of humour. The GTVH aims to be a joke representation model, indicating all aspects of the joke from the abstract joke-concept identified by the SSTH, to the language it is being expressed in. This theory defines humour by focusing on the semantic/pragmatic content of humorous utterances and texts and not their paralinguistic or prosodic aspects. Attardo (2017) claims that unlike the SSTH referring to only jokes, the GTVH 
is broadened to include (ideally) all humorous texts, of any length. Specifically, it is not limited to narrative texts, but also dramatic and conversational texts. As it is adaptable to every kind of text type, it unites the methods of several linguistic disciplines, like textual linguistics, the theory of narrativity, and pragmatics.

The authors of this theory have added new elements into humour-competence, which is 'knowledge resources.' There are six knowledge sources which are the script opposition, logical mechanism, situation, target, narrative strategy and language (Attardo 2017). Focusing our investigation on only one of these knowledge resources, the Target. It can be stated that the presence of the target in humour implies that humour can be considered as the expression of an aggressive intention. The superiority/hostility of humour maintains that humorous effect (in certain cases, laughter) results from a cooperation between us and the others or between our former self and our present self. Humour occurs when this comparison reveals that we are in some way "superior" to the others or that our present self is "superior" to our former self. Through humour, the "superior" person can "attack" and attempt to modify the behaviour of the "inferior" one (Attardo 2017). This is actually the realm of irony or even self-irony.

This theory is relevant to this study as the memes analysed in this work are all humorous texts and are conversational in nature. Thus, they aptly fall within the purview of GTVH.

\section{Pragmatics}

The general conceptualization of pragmatics as a rapidly growing field in contemporary linguistics is that it is the study of language in use. There are two schools of thought in the study of pragmatics: the Anglo-American and the (European) Continental traditions. The former sees pragmatics as the systematic study of meaning by virtue of the use of language. Cummings (2010) says that the central topics of inquiry in this school include implicature, presupposition, speech acts, deixis, reference and conversational analysis. The latter school of thought by contrast presents pragmatics as a functional perspective on all core components and 'hyphenated' areas of linguistics and beyond (Verschueren 1999). Thus, topics such as sociolinguistics, psycholinguistics and discourse analysis fall within the purview of this school. This study is a convergence of the two traditions as the memes analysed revolved around precepts of speech acts, conversational analysis and discourse analysis.

\section{Discourse}

Discourse, as understood in linguistics, is used to describe an extended stretch of language, beyond the boundaries of the sentence. The implication is that as in a sentence, there is an internal structure (subject, verb, object or complement), elements beyond the sentence also contain similar structures. Mithun (2015) sees discourse and rightly so as more than an autonomous level beyond the sentence. In this light, discourse involves how information is packaged, the flow of thought through time, the communicative and social goals of the speaker, the presumed knowledge of the audience and even more.

\section{Humour}

Humour is a literary tool that makes audiences laugh, or that intends to induce amusement or laughter. Its purpose is to break the monotony, boredom, and tedium, and make the audience's nerves relax.

While humour is relatively well studies in scientific fields such as linguistics and psychology, to date there is only a limited number of research contributions made towards the construction of computational prototypes. Most of the computational approaches to date on style classification have focused on the categorization of more traditional literature genres, such as 
fiction, SciTech, legal and others, and much less on creative writings such as humour (Simpson \& Mayr 2010).

\section{Incongruity as a humour mechanism}

In terms of humour's rhetorical and linguistic design, most researchers agree that for a piece of language or text to be funny, it must exhibit (at least) some sort of incongruity. The incongruity may operate at any level of language, which means that it can be found in the narrower features of vocabulary and grammar, or, in the wider context, in the broader units of discourse organization and social interaction (Simpson \& Mayr 2010). Puns and related forms of verbal play are good illustrations of the type of incongruity that operates in the narrower linguistic context. By contrast, pragmatic devices like irony and other types of figurative language situate the humour mechanism in an incongruity at the level of discourse. In this latter broader context, the verbal play inheres a mismatch between the conventional meanings of speech acts and the suggested meaning that those utterances have in particular contexts.

In spite of the unifying sense that an incongruity lies at the heart of its production, humour comes in many forms and guises; we are all familiar with puns, witticisms, jokes, anecdotes, slapstick, parody, sarcasm and satire. The focus of this study is on what Sinkeviciute (2019) described as conversational humour. She explains that conversational humour is an umbrella term for a different type of verbal behaviours like teasing, banter, putdowns and the likes. Whatever, the genre of the humour, the essential point is that its use introduces levity and no-seriousness into a discourse situation, inducing what might be called a 'humour footing'. Let us briefly examine some of these forms of humour that relate to the present study.

\section{a. Pun}

Pun is a play on words that produces a humorous effect by using a word that suggests two or more meanings, or by exploiting similar sounding words that have different meanings. Humorous effects created by puns depend upon the ambiguities the words entail. These ambiguities arise mostly in homophones and homonyms (literarydevices.net 2020).

\section{b. Witticisms}

Witticism is simply described as a remark that is both clever and humorous. It is a message whose ingenuity or verbal skill or incongruity has the power to evoke laughter.

\section{c. Satire /sarcasm}

A witty language used to convey insults or scorn. Satire is a technique employed by writers to expose and criticize foolishness and corruption of an individual or a society, by using humour, irony and exaggeration, or ridicule.

\section{Irony}

Irony, a linguistic and literary device in spoken or written form, in which real meaning is concealed or contradicted. That may be the result of the literal, ostensible meaning of words contradicting their actual meaning (verbal irony) or of a structural incongruity between what is expected and what occurs. It can also be a difference between the surface meaning of something that is sad and the underlying meaning. The definition of irony can be further divided into three main types: verbal, dramatic and situational. These will be described in detail below.

\section{Types of irony}

1. Verbal irony: this takes place when the speaker says something in sharp contrast to his or her actual meaning. The speaker often makes a statement that seems very direct, yet indicates that the opposite is in fact true, or what the speaker really means. So, the speaker 
feigns ignorance in order to highlight gaps in the listener's knowledge (Karoui, Benamara \& Moriceau 2019). Unlike dramatic and situational irony, verbal irony is always intentional on the part of the speaker

2. Dramatic irony: it occurs when the audience has more information than one or more characters in a work of literature. This literary device originated in Greek tragedy and often leads to tragic outcomes. There are three stages of dramatic irony: installation, exploitation, and resolution.

3. Situational irony: situational irony consists of a situation in which the outcome is very different from what was expected. There are contradictions and contrasts present in the cases of situational irony.

Other types of irony: cosmic irony, historical and Socratic irony.

\section{Irony in Discourse}

Irony is most commonly and straightforwardly defined as a form of language which means the opposite of what is asserted. This type of 'oppositional' irony is at the core of utterances like 'you're a fine friend!' when said to someone who has just let you down. This conception of irony is certainly a useful start, but it falls short in a number of respects given the broad range of strategies available for communicating irony in discourse. Consider the following three hypothetical utterances, spoken by someone during a thunderstorm:
a. 'Nice day!'
b. 'It seems to be raining'
c. 'I just love good weather'

All three of these utterances are ironic in some sense, yet it is only (a) that the speaker clearly means the opposite of what they say. The second example does not relay the opposite sense to what is uttered; it is just less than what the speaker thinks pertains to the context. Example (c) poses another problem for the traditional belief that irony is saying the opposite of what you believe. Here the speaker is saying something that they do believe to be true, so the irony resides more in a conceptual paradox between the speech act and its interaction with the physical conditions of the immediate interactive context.

There are still other distinctions in irony espoused in the literature. However, to attempt such identification risks becoming side-tracked into a comprehensive survey of ironic discourse. To keep matters simple, the following sets of definition of the concept is adopted following Simpson (2008):

Core definition: Irony is the perception of a conceptual paradox, planned or unplanned, between two dimensions of the same discursive event.

Sub-definitions: $\quad$ Irony is a perceived conceptual space between what is asserted and what is meant.

Irony is a perceived mismatch between aspects of encyclopaedic knowledge and situational context (with respect to a particular discursive event)

This study prefers the idea of a paradox in the definitions, rather than oppositeness, in order to accommodate as many distinctions of the concept as possible. The idea of irony being conceived as a 'perception' is also apt as irony cannot work without some perception of it, and while much irony undoubtedly passes us by in everyday interaction, we also perceive irony which was not planned or intended. This also signals that irony is to some extent negotiable, because we can claim 
an ironic intention even if the hearer does not identify one, or alternatively, we can rescind an ironic intention if we decide it doesn't suit or doesn't work.

\section{Memetics}

Memes were originally described by Richard Dawkins in his book The Selfish Gene (1976) as a unit of cultural transmission, or a unit of imitation. Examples of memes are tunes, ideas, catchphrases, fashion trends, tool making or architectural techniques. Just as genes propagate in the gene pool, ideas also propagate. A meme in the meme pool (much like a gene in the gene pool) can only survive if the represented knowledge evolves. Without adapting to the constantly changing conditions of the social world, the value or usability of knowledge will diminish and the meme will die. While this simple idea has been the source of much academic debate about what a meme is and how it works, the word "meme" has been picked up by internet users around the world (Shifman, 2013). As stated previously, online, a meme or "internet meme" is used to describe the rapid uptake and spread of a "particular idea presented as a written text, image, language 'move,' or some other unit of cultural 'stuff' (Knobel \& Lankshear, 2007). Another definition states that an internet meme is a neologism used to describe a catchphrase or concept that spreads in a fast way from person to person via the Internet (Encyclopaedia Britannica). An internet meme can be anything from a single word to a graphic, from a song to a video. A simple Google search of the term "internet meme" returned 62,500,000 results (March 23, 2014). Many of the first results lead to large interactive databases available as teaching tools about internet memes, or as sources of templates that internet users can use to make their own.

Internet (social media) memes, on the other hand, tend to describe recent, often short-lived fads that can rise to "internet fame" in a matter of hours or days or weeks and then fade away into nothing. Another difference is that the unit of an internet meme tends to be considered obvious and concrete such as YouTube videos or image macros that lure many spinoffs as opposed to the more abstract and controversial unit of traditional memetics research. Both types of memes however can be best understood as cultural information that is passed from person to person, but in aggregate scales into social phenomena with a wide-reaching impact on the mind sets, behaviour and actions of social groups (Knobel \& Lankshear, 2007).

\section{METHODOLOGY}

Data for this study were conversational memes drawn from Twitter, Facebook and Instagram. These conversational memes were personally obtained through screenshot over a period of two years (2017-2019) by the researcher who is an active user of Twitter, Facebook and Instagram. Thirty (30) conversational memes were purposively selected for pragmatic analysis using the workings of the discourse of humour and irony. Guises or forms of humour such as incongruity, witticism and sarcasm are employed in the analysis of the selected memes. Only thirty (30) memes were found suitable for the purpose of this study as over 93 memes were initially obtained. A basic criterion for determining a suitable meme was its conversational nature; the others not selected had pictures and text but were not conversational.

This study adopts a qualitative eclectic approach in its analysis of the data gathered. The first part of the analysis is descriptive in nature as the researcher used his intuitive knowledge as a young Nigerian who identifies with the diverse socio-cultural leanings of his country to do a pragmatic explanation of the selected memes. This intuitive analysis was subjected to further scrutiny as the researcher sought the explanation of four other young Nigerians with an active social media presence from different cultural and ethnic backgrounds. These four respondents were purposively selected by the researcher and deemed competent enough to analyze the memes. The analyses they provided were aggregated and the necessary modifications made to reflect the reality 
of the memes within the Nigerian context. The second part of the analysis situated some findings of the first analysis within already established conceptual, empirical and theoretical leanings.

\section{RESULTS AND DISCUSSION}

The data presented and analysed are conversational in nature. A conversational or interactional discourse normally involves organized turn taking. Although. the data analysed in this study are unsolicited responses to information posted on users' personal timeline, the memes are still seen as conversational. While there were many other responses to the said posts, only responses that are incongruous and evoke humorous and ironical sentiments qualify for our analysis.

\section{Data Analysis}

s/no. Data

1.

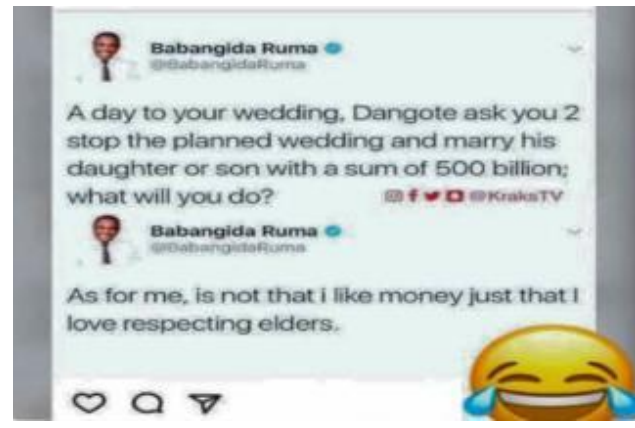

2.

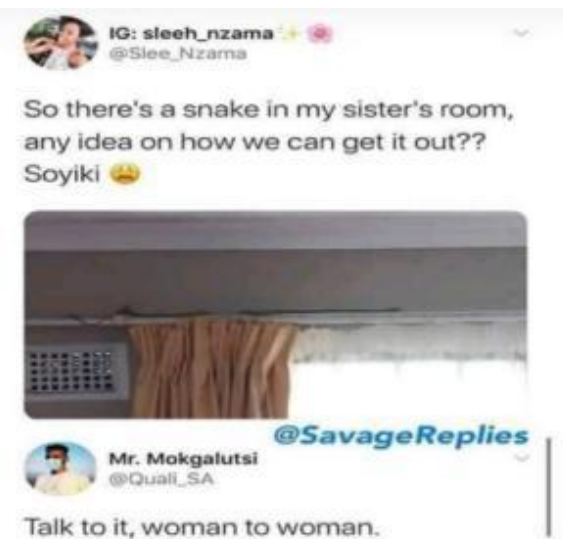

3.

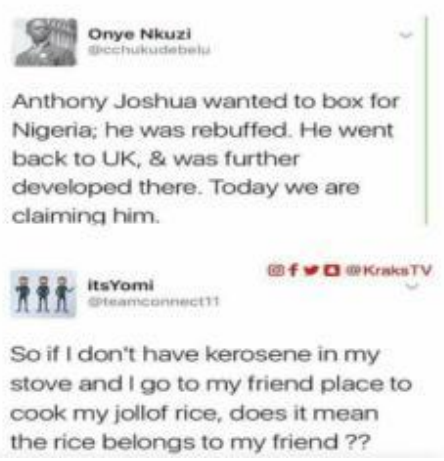

Forms of humour

Witticism

Sarcasm

Witticism

International Journal of Language and Literary Studies

\section{Pragmatic explanation of meme}

The response is clever and humorous and should not be taken on the face value. The expression 'I love respecting elders' is a smokescreen to validate the respondent's outright ditching of his bride to be for clearly pecuniary gains. Thus, the respondent conveys a serious matter as betrayal of love euphemistically.

The respondent rather than provide a solution to the to the poster's request, sarcastically refers to the snake as a woman and thus, asks the poster who is also a woman to talk to her 'fellow woman' (snake). The respondent of course is referring to the biblical account of Eve conversing with a snake. This is both humorous and ridiculous of a rather dangerous situation.

The respondent uses an incongruous but humorous and witty analogy to invalidate, in his own right, the opinion of the poster. The analogy also employs a rhetorical question to drive home the point of the respondent that there is nothing wrong if Nigeria claims Anthony Joshua because of his successes after initially rebuffing him. 
4.



Plus 2 Estates and A continent.. So you mean in this whole world there is nobody close to you to tell you that you are mad?

5.

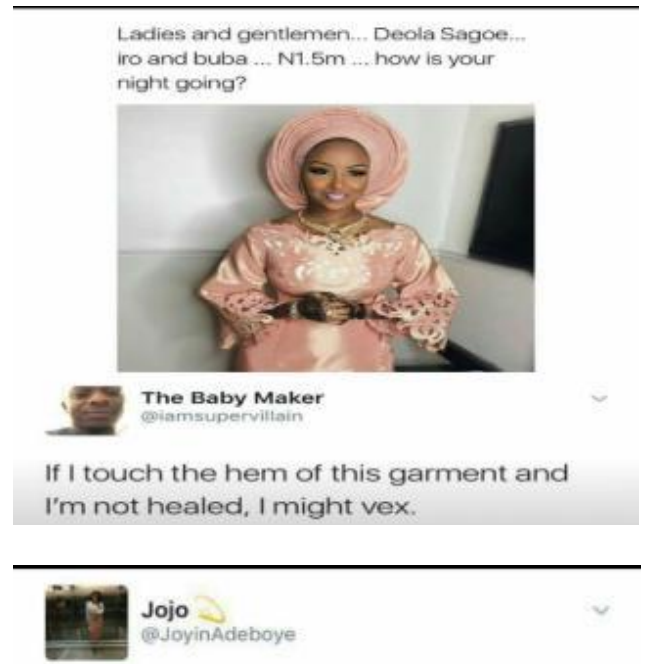

\begin{abstract}
At a wedding and this Bishop is preaching that women should lower themselves, drive small cars and dress below their means to get a husband 6

@westafrikanman

Behemoth (a)TheBlackHermit
\end{abstract}

This is why it's better to just go for the reception.

7.

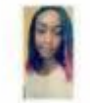

Aanu the Badass @Aanux

\section{Can we just download our husbands now?}

\section{@westafrikanman}

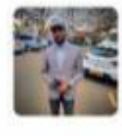

Ibadan Lord II

(1)degostee

\section{Are you a WIFI material?}

\section{Sarcasm}

Sarcasm

\section{Witticism}

Sarcasm and Pun
The respondent sarcastically reacts to the post because he considers the assertion unreal. The first sentence of the reaction is a sarcastic exaggeration and the ensuing statement is a deriding rhetorical question that exemplifies how 'gutted' or 'disappointed' the respondent feels about the post.

The respondent is sarcastic because of the exorbitant price of the 'buba' (wrapper clothing). He therefore relates the wrapper clothing to the Jesus' garment which was touched by a sick woman and she was healed. In essence, he is sarcastically asserting that if the garment cannot perform the miracle of healing when touched, then, it should not cost that much. He thus, scorns at such extravagance for a mere wrapper clothing.

The poster, apparently a woman finds the Bishop's preaching rather uncomfortable as he suggests that husbands are scarce and women must disguise to get one. The respondent cleverly hints at why in most weddings more people rather go for the reception than the church service. However, the respondent knows that the major reason is not to avoid hearing the sermon at the church but rather that people prefer the partying (food, drinks and dance) aspect of weddings.

The poster sarcastically confirms the scarcity of husbands by asking if women can find one by downloading him as though husbands were some file found on the internet. The respondent to the poster plays on the sarcastic word 'download' by replying with another internet terminology 'WIFI' which sounds like the word wife. He is in essence, asking the poster who is asking to download a husband if she's herself a good woman (wife material) ready for marriage. 
8.

(4) Africa Afremifactor

If your family worth $\$ 50$ billion.... Would you still work?

FB: @naijadiaryblog

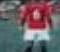

el_manuel

(i)Dondecaemo

So spending $\$ 50$ billion is not work abi

9.

auntie naz

(anazmraz.

Women have to deal with cramps, but

what do men have to deal with?

FB: @naijadiaryblog

The Baby Maker

(ciamsupervillain

Women
Witticism

Sarcasm

Sarcasm and Pun
The respondent cleverly and indirectly answers the question posed by the poster. His response shows that he clearly understood the perspective of the poster but feels it is unreasonable for the poster to ask if someone with a family worth of $\$ 50$ billion would still work when spending such a fortune is seen as work in itself. By this, the respondent wittingly implies he won't do any other work than the 'work' of spending such fortune.

The poster asserts that women regularly deal with some unique menstrual pains that men know nothing about. The poster thereby asserts that women go through a lot of pains but men are sort of fortunate. However, the respondent, a man, sarcastically reminds the poster that men deal with women who deal with such pains. In effect, the respondent is asserting that men bear more pains than women because the women transfer the aggression from the pains they bear to men.

The poster asserts that she is working towards getting a seductive body shape known as 'coke body'. This body shape mirrors the shape of the bottle of the soft drink; Cocacola. The bottle is thin at the top typifying the 'head', big at the 'chest', small at the 'waist' (where it's normally held for drinking) and big below the waist. This coke bottle shape is usually the dream of most women popularly equated with what they call figure-8. They desire a small head, sizeable or big bosoms, a tiny waist and big buttocks. The respondent sarcastically wishes the poster well in this quest but says until she attains the body shape, she should stay happy with her 'Lacasera' bottle shape. Lacasera is a soft drink with a very plain bottle shape. The respondent also played with words in evoking the image of the Lacasera bottle. 
11.

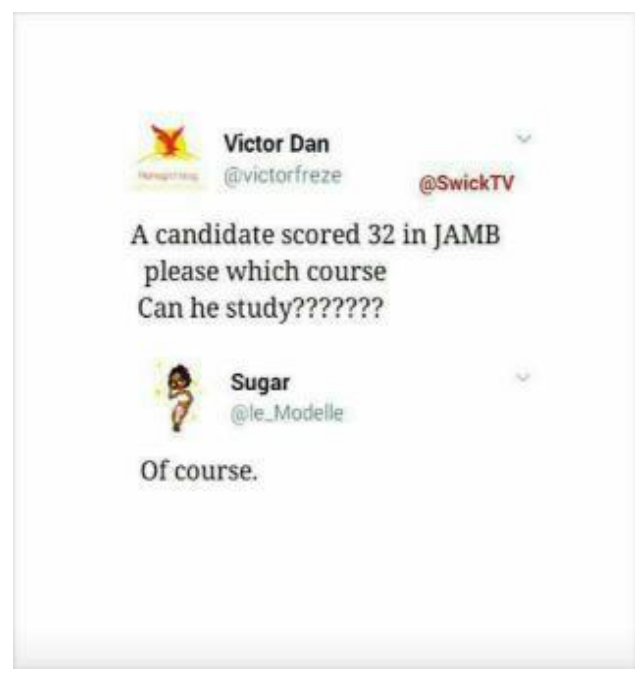

12.

SisiYèmmié.com

QSisi_Yemmie

What is the Nigerian dream?

@westafrikanman

\section{leye}

@leye_mg

to miss Nigeria from the abroad

13.

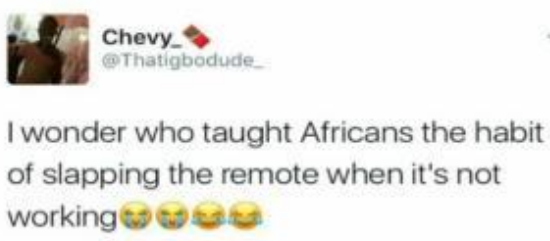

FB: @naijadiaryblog

막 Pops.

(QLe_Czarr

A slap is a reset mechanism to both

living and non living organisms.

\section{Sarcasm and Pun}

Sarcasm

Sarcasm the poster asks a question considered by the respondent to be rather ridiculous. JAMB is the unified exam for students seeking admission into a university and it has a total of 400 marks. The poster was asking for the chances of a candidate that scored 32 out of a total of 400 marks. The respondent deploys a sarcastic reply while playing on the keyword of 'course of study'. Since its obvious the candidate cannot be granted admission to study any course, the respondent ridiculously replied that the candidate can study 'Of course' which is definitely no course in any university.

The respondent's response is both humorous and ironical. One would have thought that the response to the poster should elicit patriotic sentiments. Rather the response mirrors a lack of patriotic enthusiasm. The respondent rather wants to leave the country by all means and 'miss' happenings in Nigeria from outside the country. The use of the definite article 'the' to precede abroad is basically for humorous emphasis and entails that any other country outside Nigeria will do.

The poster made reference to a remote device that controls electronic devices. These devices are usually slapped in African home when they are not functioning and most times they start working after they are slapped. The respondent agrees with the poster but ironically relates the slapping of remotes to living organisms. By such connection, the respondent brings to mind the commonplace slapping of wards by their parents in African each time such wards misbehave. Such slap is seen as a 'reset mechanism' which helps bring the wards to their right senses. 
14.



I'm just wondering which lion told you this.

15.

$\pi$ @sageseid

What is it about Lagos that makes

finding love so hard?

\section{@westafrikanman}

Ankle Obama

@Sick_Sage

Traffic

16.



Mphonini

FB: @naijadiaryblog

(amphonini_boo

Being lazy is disrespectful to those who believe in you

The Baby Maker

@iamsupervillain

Who asked them?
Sarcasm

Sarcasm

witticism

Sarcasm
The poster makes a post about some believed characteristic of lions as it pertains their hunting habits. The statement is also seen as a motivational quote to spur 'lionlike' (metaphor) humans to action. The respondent criticizes the assertion of the poster by giving a rather ridiculous response. The respondent knows that lions cannot communicate with humans let alone tell humans their hunting techniques. So, the respondent sarcastically dispels the assertion of the poster and also employed the used of an emoji or smiley depicting a 'confused face'.

and The poster asks a rather harmless question about finding love in Lagos. The response is rather sarcastic and witty. The response is that traffic in Lagos is what makes it difficult to find love in Lagos. The traffic situation in Lagos is so bad that commuters spend very reasonable hours in traffic on a daily basis. Vehicular traffic is practically something that people residing in Lagos are already used to. So, the respondent asserts that time intended to finding love in Lagos is lost in traffic. Also, the respondent may also intend to mean that there is also human traffic in the state. Lagos is the most Populated city in Africa with over 21 million people.

The poster states some fact about being industrious. The respondent sarcastically opines that he did not ask anyone to believe him as such he does not care if people feel disrespected or disappointed at his being lazy. The poster made a valid point but the respondent in trying to justify his laziness asked a rather rhetorically sarcastic question. 
17.

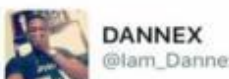

Can you take a bullet for your ex?

FB: @naijadiaryblog

MR President

Qduchesskk

Where am I taking it to?

18.

\section{Jigga $J$}

Jigyydutfe

If your money comes from your parents don't talk to me about hustle

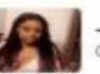

You think getting money from african parents isn't hustling?

19.

Nomalizo

@Lizo_Thwala

\section{PUBLIC ANNOUNCEMENT!!!}

Please leave people's men alone. Find

your own.

Kind regards.

Management.

FB: @naijadiaryblog

Bright Chinyimba Jr.

@Chinyimbast

Who said we want to be left alone? Speak

for your man please.

\section{Sarcasm}

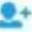


20.

Nathan Allen 0

(ew)or

What is this chapter of your life called?

Be creative

FB: @naijadiaryblog

thatDACboy

@DamieAjibz

Temporarily unable to dispense cash

21.

ISII Alexander III

Sarcasm

So this lady said a guy is too faithful and

she doesn't like it. Hold on ... So y'all

want a guy that doesn't cheat but not

too faithful? 9 然

Mikl OnlyGodCanJudgeMe

fabolous3d

FB: @naijadiaryblog

People that remove their eyebrows and

draw it back with a pencil, what were

you expecting ?!

22.

FB: @naijadiaryblog

Snoop Dawger

(9)boymaison

Are you calling Solomon a fool?

Sarcasm
Witticism

The respondent cleverly but humorously describes his current situation in life in a way akin to an Automated Teller Machine (ATM). When the cash in an ATM is exhausted, the machine displays the message 'temporarily unable to dispense cash'. The respondent, thus, describing his current situation in life this way, implies that he has exhausted all the money he has and is in a dire need for money. Simply put, he is broke.

The poster reports a rather confounding situation about ladies wanting a man who doesn't cheat but is not too faithful. The poster seems bemused by such thoughts but the respondent isn't. He rather draws an ironical comparison of the situation to the make-over habit of women who shave off their natural eyebrows and draw it back with a pencil. He sarcastically asks the poster a rhetorical question based on this analogy. He concludes with a corresponding emoji of 'tears of joy'.

The poster makes a very clear assertive statement that hinges on fidelity for men. He claims that one girl is enough for each man. The respondent sarcastically draws the poster's attention to King Solomon in bible times. He was known in the scriptures as a very wise king; however, the scriptural account did show that he had 700 wives and 300 concubines. So, the respondent makes reference to a known example of one who had more than one girl but was a very wise person to support his disapproval of the post. In essence, the poster does not believe in the 'one girl is enough' narrative. 
23.

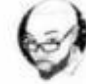

Nigerian God

(eEchecrates

Ladies: Why won't y'all let us continue

to sleep when you wake up before us?

Help us understand

FB: @naijadiaryblog

Georgia-Lorene

eigeorgia_lorene

When the woman of your dreams is

awake, why are you still dreaming??

24.

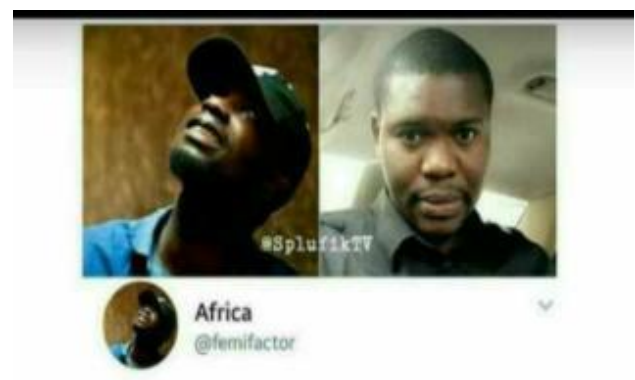

Would you feel bad if you don't get served at a wedding you travelled to another state to attend

eSpluf1kTV

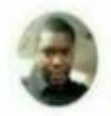

Chidi Okereke

echydee

It's like they don't want to have children.

25.

OFENTSE

Gotentseprokid

Anyone who tries to put me down must know that I will always rice

TK

Tunde [

@Tunnyking

As a human bean, I yam in full support of this if only you can meat up to expectations at the appointed thyme to avoid beefs

\section{Sarcasm}

Witticism

Sarcasm

Sarcasm and Pun and The poster, apparently a man complains that most ladies will not allow their man continue sleeping once they (the ladies) are awake. The respondent, obviously a lady, opines that men need not sleep when their women are awake because that would be dangerous to the 'fidelity narrative' as the men could be dreaming of another lady if they continue sleeping when their ladies are awake. In fact, she cleverly supports the rather ironical assertion by massaging the ego of men, thus, using the phrase 'the woman of your dreams'.

With a situation that is commonplace and most often happens during wedding ceremonies, the poster asks a question. The respondent's sarcastic reaction shows that he takes exception to not being served at wedding ceremonies he travels to attend. It is often an issue serving guests in wedding ceremonies in a typical African setting because of the number of guests invited and those who also attend uninvited. Most guests end up not getting anything to eat or drink. The respondent knows this fact, but sarcastically opines that he would rather go diabolical and make the couple childless should he not eat at their wedding.

The poster uses the word 'rice' instead of 'rise' to make an assertive statement. This may or may not be unintentional. The respondent plays on the word 'rice' and sarcastically constructs his reaction to reflect words that have to do with food. So rather than write ' as a human being I am in full support of this if only you can meet up to expectations at the appointed time and avoid beefs (a slang that means grudge). The drift is clearly meant for humour as the thought pattern of the reaction basically has no connection to the poster's discourse. 
26.



\section{Sounds like native doctor instructions to me.. hope you didn't eat it?}

27.

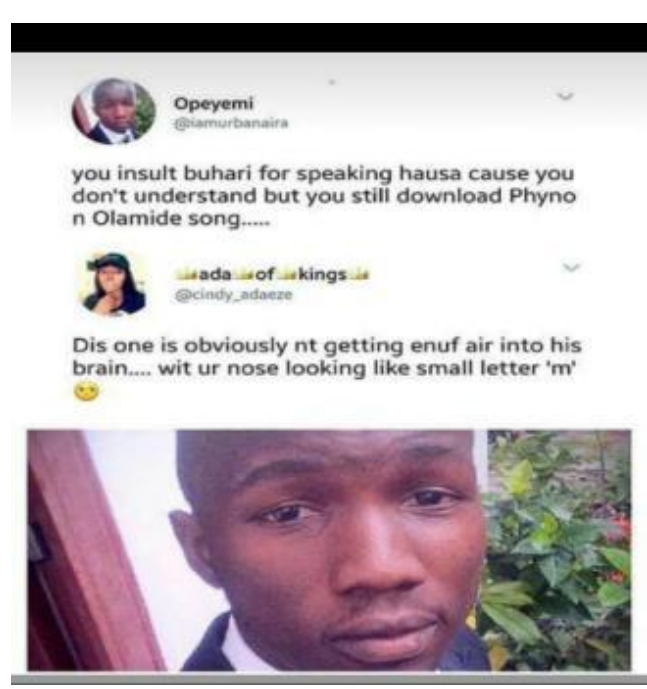

28.

groovee@grooveeshakes

Guys plssss what fairly affordable but super good restaurants in VI can I take me mum to on a date

\section{@westafrikanman}

There's a popular one called Ryce At Héaum. All homemade food. Lovely
Sarcasm

\section{Sarcasm}

Sarcasm and Pun
The poster describes a somewhat romantic scene she experienced the day before and the respondent comment was rather sarcastic. One would have expected a reaction that falls in line with the sentiments and psychological state of the poster. The reaction was to the contrary, aimed at instilling fear and suspicion in the mind of the poster. The respondent concludes by asking a ridiculous question, knowing full well that the poster is only reporting an event that has already taken place.

The poster makes a clear observation from his own perspective that seems to be a disconnect in the reasoning of some people. The respondent intentionally avoids the meat of the discourse and rather focuses on the nose of the poster as seen on his display picture. The respondent sarcastically addresses the structure of the nose of the poster and opines that as a result of how the nose is, the poster is not getting enough air to breathe for the optimal functioning of his brain. She critically looks at the structure of the nose and humorously asserts that it looks like the lowercase letter ' $\mathrm{m}$ '.

The poster is looking for recommendations and thus, asks an innocuous question. The respondent rather than make recommendations for the poster, makes fun of the post by playing on some words. The word 'Ryce' was used by the respondent instead of rice, the word 'Héaum' intead of home. She concludes by saying 'all homemade food. Lovely'. Thus, the respondent is sarcastically telling the poster to make rice at home and serve the mum because there are no fairly affordable restaurants in Victoria Island (VI), Lagos. 
29.

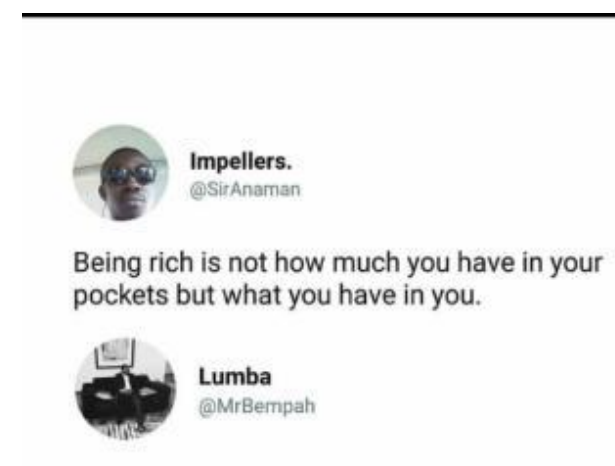

Use your intestines to buy beans ok?

30.

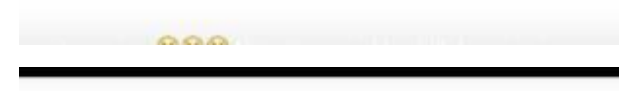

8. Disturbinglbadank:

If you laugh at other people's conditions, you will be like them in

future... @1hatyorubaguy

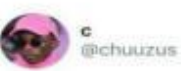

Bill Gates LMAOO. Bill Gates is a Billionaire LMAOOOO!!! @e
Sarcasm

Sarcasm

\section{DISCUSSION OF FINDINGS}

The analysis of the data presented in this work showed that on a general note the responses (reactions) to the posts were funny and not the kind of response the posters anticipated. The reactions all exhibit some form of incongruity and were also verbally ironical. Thus, the memes qualify as humorous as their analyses align with the assertion of Simpson \& Mayr (2010) who describe humour's rhetorical and linguistic design as such that most researchers agree that every piece of language or text classified as humorous must be funny and exhibit at least some form of incongruity.

In consonance with one of the six knowledge sources discussed in the General Theory of Verbal Humour (GTVH) as espoused by Attardo (2017), the memes analyzed in this study all have 'targets. This precept of 'target' knowledge resource explains that through humour, the 'superior' person can 'attack' and attempt to modify the behaviour of the 'inferior' one. In the light of our data and analysis, the posters on Facebook, Twitter and Instagram who posted their thoughts on their timeline are the 'inferior one' while the unsolicited respondents or reactors to the posts are the 'superior one'. Thus, the reactors use humour to as Attardo (2017) puts it 'attack' and attempt to modify the thought-pattern of the 'inferior one' (the poster). This 'attack' on the posters can be clearly seen from the reactors in data $2,3,4,5,7,8,9,10,14,16,18,19,22,25,26,27$ and 29.

The nature of most of the posts generating humorous comments from different respondents can be classified into speech acts in line with Allan's (1994) classification. In line with Austin's 
classification, Mai Thi \& Aiden (2020) explains that speech acts can be classified into five groups of declaratives, directives, expressives, commissives, and representatives. It is observable from the data analyzed that the posters made expressive and assertive statements on their timelines. Eighteen (data 1,2,5,6,7,8,9,11,12,15,17,20,21,23,24,26,27 and 28) out of the 30 memes were expressives while the remaining twelve $(3,4,10,13,14,16,18,19,22,25,29$ and 30) were assertives. Allan (1994) describes expressives as a speaker's attitude to a certain state of affairs specified in the propositional content. There is no direction of fit; it reflects a variety of psychological states while assertives are propositions with truth value that express the speaker's belief. A line of connection one can be seen between expressives and assertives is that they reflect the speaker's state of affairs or belief. So, the point is that the posters are only expressing their belief or psychological state on their own timelines which is of course their right and does not warrant the 'attack' meted on them by the reactors

Specifically, three forms and guises of humour were identified in the reactions to the originating posts. They are sarcasm, witticism and pun. Sarcasm was found in 23 out of the 30 memes analyzed thus, accounting for 77 percent of the guises. Witticism came a distant second with pun the least used. The fact that witticisms and puns were seldom used is obvious because the use of both requires some level of mental and literary wit. This is true because, earlier I described witticism as a message whose ingenuity or verbal skill or incongruity has the power to evoke laughter while puns are achieved by playing on words or exploiting similar sounding words that have different meanings. The research also shows that $90 \%$ of the conversational memes gathered and analyzed came from twitter. This is not surprising because twitter is seen as a more sophisticated social medium as it has fewer subscribers when compared to Facebook and Instagram. Instagram was created on October 6, 2010 while Twitter was created in March, 2006, yet Instagram has more than double the subscribers of Twitter. According to Investopedia.com, high school graduates are less likely to use Twitter compared to college graduates because Twitter users tend to be more affluent and live in the city. Twitter can be seen elite medium sort of and it will not be out of place to posit that social media users on twitter will tend to be are more creative in writing than those on Facebook and Instagram This is evidently so because to create humorous memes require some level of linguistic creativity as confirmed by Stojchevska \& Shalveska (2018).

Some of the memes analyzed also contained intentional misspelling of words to create humour. In datum (7), the word 'wife' was intentional misspelt as 'WIFI', also in datum (25), the poster intentionally misspelt 'rice'. I say the misspelling was intentional because even the poster's pseudo-name was misspelt as 'OFENTSE' instead of OFFENSE. The reactor obviously for hysterical reasons went on a misspelling spree as earlier explained in the analysis. The abbreviation LMAO (Laughing My Ass Out) was also used in datum (30). This intentional misspelling and use of abbreviations in internet memes were clearly observed by Stojchevska \& Shalveska (2018) who explained that intentional mistakes and abbreviations are notable linguistic features of memes. They clarified that intentional mistakes are made by the author in order to retain the original meme's integrity and format while abbreviations are used in memes to convey meaning in as little words/symbols as possible.

\section{CONCLUSION}

This study pragmatically examined the ludic function of language within the confines of the discourse of humour and irony with emphasis on memes from Twitter, Facebook and Instagram. While different studies have been carried out on the ludic function of language, there may be very few or even none that has looked at memes on Twitter, Facebook and Instagram. This study is significant in the field of discourse analysis and pragmatic linguistics in African studies. This claim 
is premised on the fact that the memes presented and analyzed are all localized within the African setting in general and the Nigerian context in particular.

\section{REFERENCES}

Allan, K. (1994). Speech act classification and definition. In Ashe, R. (ed.), Encyclopedia of language and linguistics. Oxford: Pergamum Press. 8, 4124-4127

Attardo, S. (2001). Humorous texts: a semantic and pragmatic analysis. Berlin: Walter de Guyter.

Attardo, S. (2017). The general theory of verbal humor. In Attardo, S. (ed.), The Routledge handbook of language and humor. New York and London: Routledge.

Bloor, M. \& Bloor, T. (2013). The practice of critical discourse analysis: an introduction. New York: Routledge.

Cummings, L. (ed.) (2010). The pragmatics encyclopedia. London and New York: Routledge Taylor and Francis Group.

Henry, F. \& Tator, C. (2002). Discourse of domination: racial bias in the Canadian English-langauge press. Toronto: University of Toronto Press Incoporated.

Karoui, J., Benamara, F., \& Moriceau, V., (2019). Automatic detection of irony: opinion mining in microblogs and social media. London and USA: IDTE Ltd and John Wiley and Sons, Inc.

Knobel, M. \& Lankshear, C. (2007). Online memes, affinities and cultural production. In Knobel, M \& Lankshear, C. (eds.), a new literacies sampler. New York: Peter Lang. 199-227.

Mai Thi, T. \& Aiden, Y. (2020). Keeping it real: Vietnamese-English pragmatic representations in EFL textbooks. International Journal of Language and Literary Studies. Retrieved 21st May, 2020 from https://doi.org/10.36892/ijlls.v2i1.105

Mithun, M. (2015). Discourse and grammar. In Tannen, D., Hamilton, H.E. \& Schriffin, D. (eds.), The handbook of discourse analysis. 2nd edn. West Sussex: Wiley Blackwell.

Shifman, L. (2011). Anatomy of a YouTube meme. In Sage Journal. Retrieved on the 20th April, 2020 from https://doi.org/10.1177

Shifman, L. (2013). Memes in a digital world: reconciling with a conceptual trouble maker. In Journal of Computer-Mediated Communication. Retrieved on the 20th April, 2020 from https:/doi:10.1111/jcc4.12013

Sinkeviciute, V. (2019). Conversational humour and (im)politeness. Amsterdam/Philadelphia: John Benjamins Publishing Company.

Simpson, P. (2008). “"That's not ironic, that's just stupid”, Perspectives on the discourse of irony', mimeo, Queen's University, Belfast.

Simpson, P. \& Mayr, A. (2010). Language and power. London and New York: Routledge Taylor and Francis Group.

Stojchevska, B.K. \& Shalveska, E. (2018). Internet memes and their socio-linguistic features. European Journal of Literature, Language and Linguistic Studies. No 4 Vol.2. 158-169.

Verschueren, J. (1999). Understanding pragmatics. London: Arnold.

https://dictionary.cambridge.org/dictionary/eng assessed on the 9th April, 2020. 
https://literarydevices.net/pun assessed on the 9th of April, 2020.

https://britannica.com/topic/meme (Encyclopaedia Britannica) assessed on the 15th April, 2020.

https://en.m.wikipedia.org/wiki/internet-meme assessed 20th May, 2020

https://datareportal.com/social-media-users assessed 20th May, 2020

https://investopedia.com/articles/markets/100215/twitter-vs-facebook-vs-instagram-who-targetaudience.asp assessed 20th May, 2020

\section{AUTHOR'S BIO}

Joshua, Samuel Fubara is a lecturer who teaches Syntax, Discourse Analysis and Pragmatics at the University of Port Harcourt, Nigeria. He bagged a First Class in Linguistics and Communication Studies and a distinction in Linguistics in his Masters and PhD from the same institution. 